OPEN ACCESS

Edited by: Gustavo Henrique Goldman, University of São Paulo, Brazil

Reviewed by: Vasantha-Srinivasan Prabhakaran, St. Peter's University, India Cécile Neuvéglise, Institut National de la Recherche Agronomique (INRA), France

${ }^{*}$ Correspondence: Shaukat Ali aliscau@scau.edu.cn

Specialty section This article was submitted to Fungi and Their Interactions, a section of the journal

Frontiers in Microbiology

Received: 21 March 2019

Accepted: 23 July 2019

Published: 13 August 2019

Citation:

Wu J, Yu X, Wang X, Tang $L$ and Ali S (2019) Matrine Enhances the

Pathogenicity of Beauveria brongniartii Against Spodoptera litura

(Lepidoptera: Noctuidae).

Front. Microbiol. 10:1812.

doi: 10.3389/fmich.2019.01812

\section{Matrine Enhances the Pathogenicity of Beauveria brongniartii Against Spodoptera litura (Lepidoptera: Noctuidae)}

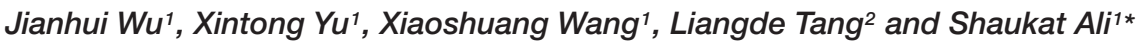 \\ ${ }^{1}$ Key Laboratory of Bio-Pesticide Innovation and Application, Engineering Research Centre of Biological Control, South \\ China Agricultural University, Guangzhou, China, ${ }^{2}$ Key Laboratory of Integrated Pest Management on Tropical Crops, \\ Ministry of Agriculture, Environment and Plant Protection Institute, Chinese Academy of Tropical Agricultural Sciences, \\ Haikou, China
}

The repetitive application of pesticides at high doses against Spodoptera litura Fabricius has resulted in development of pesticide resistance and harmful effects to the natural environmental. Hence, finding alternate pest control strategies, such as entomopathogenic fungi or their application in combination with other natural chemicals, is of great importance to solve the abovementioned problems. This study presents the toxic effects of Beauveria brongniartii and matrine (individual or in combination with each other) against tobacco cutworm (S. litura). Different matrine treatments caused a dose dependent increase in $S$. litura mortality at different time intervals. The biological parameters of $B$. brongniartii (germination rate and average daily mycelia growth) were not inhibited by different matrine treatments. Different conidial concentrations of B. brongniartii caused significantly different mortalities of 2nd instar S. litura larvae at different time intervals. Different combined treatments of $B$. brongniartii and matrine showed a significant synergistic effect against $S$. litura under laboratory and semifield conditions. The current findings showed a strong synergistic action for combined application of $B$. brongniartii and matrine against $S$. litura. Our results will provide baseline information on combined application of entomopathogenic fungi and natural chemicals in integrated pest management programs against $S$. litura.

Keywords: natural chemicals, entomopathogenic fungi, matrine, synergism, Spodoptera litura

\section{INTRODUCTION}

Spodoptera litura (Fabricius) (Lepidoptera: Noctuidae) also known as tobacco cutworm is a major threat to majority of cropping systems because of its generalist herbivores behavior. Almost 389 plant species from 109 families have been documented as host plants of S. litura (Qing et al., 2006).The management of $S$. litura is mostly carried out through heavy pesticide which is causing many adverse effects to human health as well as to other components of our environment (Ishtiaq et al., 2012; Ahmad and Mehmood, 2015). Apart from this, the repetitive pesticide application is making S. litura resistant to these chemicals. Zhang et al. (2014) has reported the development of moderate to high insecticide resistance by $S$. litura against different pesticides such astubefenozide, 
indoxacarb, spinosid, and emamectin benzoate. Hence, finding alternate pest control strategies such as natural control agents is need of the hour to solve the above-mentioned problems (Revathi et al., 2014).

Matrine is a naturally occurring heterocyclic compound derived from quinolizidine which is isolated from the roots of Sophora flavescens and Sophora alopecuroides (Fabales: Fabaceae) (Mao and Henderson, 2007; Zhang et al., 2012; Cheng et al., 2018). Matrine is known to have a wide range of medicinal activities like anti-cancer, anti-inflammatory, antimicrobial, antiviral, antifibrotic, and immunoinhibitory, etc. (Hu et al., 2010; Chao et al., 2013; Sun et al., 2016). Matrine is one of the most used traditional medicines in China being used for the treatment of diseases such as cancer, viral hepatitis, colpitis, skin inflammation, etc. (Nakajyo et al., 1983; Zhang et al., 2009, 2012). Matrine is also a well-known botanical pesticide because of its broad spectrum insecticide activities, anti-plant virus activity and fungicidal activity as well as being friendly to the environment (Li et al., 2010; Zanardi et al., 2015; Ali et al., 2017). Recent studies have shown the use of matrine in an isolated form or in a mixture with other botanical, synthetic and microbial pesticides to control different insect pests (termites, whiteflies, aphids, leaf hoppers, caterpillars and mites), fungal and bacterial diseases and nematodes in china (Yang and Zhao, 2006; Liu et al., 2007; Mao and Henderson, 2007; Li et al., 2010; Ali et al., 2017). Matrine has been commercialized under different trade names; however, their insecticidal activities are lower than the popular insecticides introduced by international pesticide companies during the last few years (Cheng et al., 2018). Based on the good biological activity and wide range it will be interesting to develop a practical strategy for preparation of insecticidal formulations in which matrine can be used in mixture with other natural pest control agents.

Entomopathogenic fungi are promising agents in regulation populations of S. litura (Chaudhari et al., 2016; Nguyen et al., 2017; Namasivayam et al., 2018; Sahayaraj et al., 2018; Kaur et al., 2019; Yang et al., 2019). Fungi belonging to genus Beauveria (Hypocreales: Cordycipitaceae) are one of the most common insect pathogenic fungal species, which can act as an alternative to pesticides against S. litura (Borja et al., 2018; Dhar et al., 2019; Yang et al., 2019). Beauveria species are known to cause widespread epizootics of insect populations because of their saprophytic behavior (Leathers et al., 1993). Beauveria bassiana (Balsamo), B. brongniartii (Saccardo), and B. amorpha (von Hoehnel) are the most effective as well as highly used insect pathogenic species belonging to genus Beauveria (Gupta, 2002). Beauveria brongniartii (Sacc.) Petch is a promising fungal pathogen, which is virulent against different insect species (Wada et al., 2010, 2016; Fan et al., 2013; Liu et al., 2016; Soni et al., 2017). Liu et al. (2016) determined the toxicity of B. brongniartii strain NEAU30503 against larval instars of two pest species belonging to order Lepidopetra (Xestia c-nigrum Linnaeus and Agrotis ypsilon Rottenberg). Their results showed $\mathrm{LC}_{50}$ values of $7.28 \times 10^{7}$ and $3.85 \times 10^{7}$ conidia/ml against $X$. nigrum amd A. ypsilon, respectively. The higher environmental tolerance, longer persistence and higher infection ability makes B. brongniartii a potential biocontrol agent against S. litura management. B. brongniartii isolate SB010 was used in this study due to its considerably higher pathogenic activity against different insect species observed during our recent studies (Huang, 2019; Ou, 2019).

This study deliberates the possible synergistic action of matrine and $B$. brongniartii against S. litura in laboratory and semi field conditions as both of these agents possibly affects their host through same site of action. Matrine is known to target insect acetylcholine receptors, which in turn effects acetylcholinestrase production (Liu et al., 2007). B. brongniartii enters its insect hosts through the penetration of their cuticle unlike the other microbial pathogens (bacteria, or viruses) which needs ingestion to induce disease (Wang et al., 2004). $B$. brongniartii is known to secrete different biochemicals such as enzymes and secondary metabolites during cuticle degradation, colonization and proliferation of host hemocoel (Thomas and Read, 2007; Fan et al., 2013). Host death is often due to a combination of the action of a fungal toxin, the physical obstruction of blood circulation, nutrient depletion and the invasion of organs (Fan et al., 2013). Beauveria species produce a secondary metabolite named bassianolide, which can affect acetylcholine receptors of insect muscles, reducing the production of acetylcholinesterase (Xu et al., 2009). Initially, the effects of multiple doses of matrine on conidial germination and mycelial growth of $B$. brongniartii were studied. Then, multiple dose levels of matrine, B. brongniartii, and their combinations were tested against $S$. litura as the majority of previous synergistic studies of matrine with other control agents (Hwang et al., 2009; Li et al., 2010) have used one level of each component. We hope that our results will provide baseline information on combined application of entomopathogenic fungi and natural chemicals in integrated pest management programs against $S$. litura.

\section{MATERIALS AND METHODS}

\section{Insect Rearing}

Semi synthetic artificial diet prepared by following David et al. (1975) was used to rear S. litura at $26 \pm 2^{\circ} \mathrm{C} ; 65 \pm 5 \%$ relative humidity and $16 \mathrm{~h}: 8 \mathrm{~h}$ (light: dark) photoperiod.

\section{Insecticide and Fungal Preparations}

Matrine (purity 95\%) was obtained from Guangdong New Scene Bioengineering Company, Yangjiang, China. A stock solution of matrine $(1.0 \mathrm{mg} / \mathrm{mL})$ was prepared by dissolving matrine powder in methanol. Lower concentrations were prepared through serial dilutions by using methanol as solvent.

Beauveria brongniartii isolate SB010 originally isolated from soil obtained from the repository of Key laboratory of biopesticides innovation and application of Guangdong Province, South China Agricultural University, Guangzhou, China was used during these studies. Fungal inoculum $\left(1 \times 10^{9}\right.$ conidia/mL) for this study were prepared by following Ali et al. (2017). Lower conidial concentrations were prepared by serial dilutions with deionized water containing $0.02 \%$ Tween 80 . 


\section{Effect of Matrine on Conidial Germination, and Mycelia Growth of B. brongniartii}

The effect of matrine on germination of $B$. brongniartii was studied by adding five different concentrations of matrine $(0.05$, $0.125,0.25,0.5$, and $1.0 \mathrm{mg} / \mathrm{L}$ ) to $100 \mathrm{~mL}$ sterilized sabouraud dextrose liquid culture medium (SDA) in $250 \mathrm{~mL}$ Erlenmeyer flasks whereas culture medium without matrine served as control. $B$. brongniartii was added to each treatment and control flasks to final concentrations of $1 \times 10^{4}$ conidia/mL. The experimental setup was incubated in a rotary shaker at $180 \mathrm{rpm}$ and $26 \pm 2{ }^{\circ} \mathrm{C}$ for 3 days. The number of germinated conidia was observed every $24 \mathrm{~h}$ and transformed to percent germination. Fungal germlings having germ tube lengths longer than spore diameter were counted as germinated. The whole experiment was repeated thrice with fresh conidial suspension prepared every time.

The influence of matrine on radial growth of $B$. brongniartii was observed by layering five different concentrations of matrine $(0.05,0.125,0.25,0.5$, and $1.0 \mathrm{mg} / \mathrm{mL})$ on solidified PDA disks (PDA medium $(10 \mathrm{~mL})$ was poured into petri dishes $(9 \mathrm{~cm})$ and left to solidify for $2 \mathrm{~h}$ ) and left to dry overnight. PDA plates without matrine layer served as control. Mycelial disks of $B$. brongniartii ( $2 \mathrm{~cm}$ diameter) were inoculated to different treatments and control Petri plates. The whole experimental setup was incubated at $25 \pm 2{ }^{\circ} \mathrm{C}, 80 \pm 5 \%$ relative humidity and $16 \mathrm{~L}$ : $8 \mathrm{D}$ photoperiod. The colony diameters were measured by using the method of Ali et al. (2009) on daily basis until 7 days.

\section{Efficacy of B. brongniartii Against S. litura}

Five different conidial concentrations $\left(1 \times 10^{5}, 1 \times 10^{6}, 1 \times 10^{7}\right.$, $1 \times 10^{8}$, and $1 \times 10^{9}$ conidial $/ \mathrm{mL}$ ) were added to the molten state of artificial diet prepared by following David et al. (1975). Artificial diet without the addition of fungal conidia served as control. Freshly molted 2nd instar S. litura larvae were individually placed in plastic cups ( $4 \mathrm{~cm}$ diameter) to feed on $1 \mathrm{~g}$ of pre-treated as well as control diet. The cups were incubated at $25 \pm 2{ }^{\circ} \mathrm{C}, 80 \pm 5 \%$ relative humidity and $16 \mathrm{~L}: 8 \mathrm{D}$ h photoperiod. There were 20 larvae used for each treatment and the whole experimental setup was repeated thrice. Larval mortality was recorded on a daily basis for 7 days. Fungal infection of larvae was identified by the darker body color and, later on, by outgrowth of mycelia from larval bodies.

\section{Efficacy of Matrine Against S. litura}

Five different matrine concentrations $(0.05,0.125,0.25,0.5$, and $1.0 \mathrm{mg} / \mathrm{L}$ ) were added to the molten state of artificial diet. Artificial diet without the addition of matrine served as control. Freshly molted 2nd instar S. litura larvae were individually placed in plastic cups ( $4 \mathrm{~cm}$ diameter) to feed on one gram of pretreated as well as control diet. There were 20 larvae used for each treatment and the whole experimental setup was repeated thrice. The whole experimental setup was incubated at $25 \pm 2{ }^{\circ} \mathrm{C}$, $80 \pm 5 \%$ relative humidity and 16L: $8 \mathrm{D}$ h photoperiod and larval mortality was recorded on daily basis for 7 days.

\section{Toxicity of $B$. brongniartii and Matrine Alone or in Combination With Each Other Against S. litura Under Laboratory Conditions}

Individual or joint treatments of B. brongniartii and matrine as shown in Table 1 were added to the molten state of artificial diet. Artificial diet without the addition of fungal conidia served as control. Freshly molted 2nd instar S. litura larvae were individually placed in plastic cups ( $4 \mathrm{~cm}$ diameter) to feed on $1 \mathrm{~g}$ of pre-treated as well as control diet. The experimental setup was incubated at $25 \pm 2{ }^{\circ} \mathrm{C}, 80 \pm 5 \%$ relative humidity and $16 \mathrm{~L}$ : $8 \mathrm{D} \mathrm{h}$ photoperiod. The mortality was observed as described in above section.

\section{Toxicity of $B$. brongniartii and Matrine Alone or in Combination With Each Other Against S. litura Under Greenhouse Conditions}

The efficacy of Individual or joint treatments of B. brongniartii and matrine (Table 1) against 2nd instar S. litura larvae were also tested under greenhouse conditions by following the method of $\mathrm{Xu}$ et al. (2011) with some modifications. Freshly molted 2nd instar S. litura larvae were placed on cabbage leaves. Ten larvae were placed on each leaf and three leaves were selected from each plant making a total of 30 larvae per plant. Different treatments were sprayed on leaves with $500 \mathrm{~mL}$ hand sprayer following Vidal et al. (1998). The treated leaves were covered with plastic screen to avoid the escape of insects. The leaves of control groups were sprayed with $0.02 \%$ Tween 80 . The entire experiment was repeated three times at different dates. Larval mortality was recorded on a daily basis for 7 days.

\section{Data Analysis}

Percent of germination and radial growth of $B$. brongniartii was analyzed through one-way ANOVA and means were separated by Tukey's HSD test (Tukey's < 0.05). Mortality values of S. litura in response to different concentrations of $B$. brongniartii and matrine at different time intervals were arcsine square-root transformed followed by two-way ANOVA and means were separated by Tukey's HSD test (Tukey's < 0.05), when F-value

TABLE 1 | Combinations of Beauveria brongniartii and matrine tested in efficacy studies.

\begin{tabular}{lcc}
\hline Treatment & Beauveria brongniartii(conidia/mL) & Matrine(mg/L) \\
\hline T0 & 0 & 0 \\
T1 & 0 & 0.5 \\
T2 & 0 & 1.0 \\
T3 & $1 \times 10^{8}$ & 0 \\
T4 & $1 \times 10^{9}$ & 0 \\
T5 & $1 \times 10^{8}$ & 0.5 \\
T6 & $1 \times 10^{8}$ & 1.0 \\
T7 & $1 \times 10^{9}$ & 0.5 \\
T8 & $1 \times 10^{9}$ & 1.0
\end{tabular}


was significant. All data analysis was performed by using SAS 8.1 software (SAS Institute, 2000).

The presence of possible synergism between $B$. brongniartii and matrine was calculated by following Xu et al. (2011). Initially, the corrected mortality over control was calculated by following equation (Abbott, 1925).

Corrected mortality $(M)=$

(Mortality in response to - Mortality in response to treatment control)

( 1 - Mortality in response to control)

The expected mortality in response to different combined treatments of $B$. brongniartii and matrine as well as chi square values to determine the kind of interaction were calculated through following equations

$$
\text { Expected mortality }\left(M_{\mathrm{e}}\right)=M_{\mathrm{A}}+M_{\mathrm{B}} \times\left(1-M_{\mathrm{A}}\right)
$$

where $M_{\mathrm{e}}$ is the expected mortality for additive mortality; $M_{\mathrm{A}}$, $M_{\mathrm{B}}$ and $M_{\mathrm{AB}}$ are the observed mortalities for B. brongniartii, matrine and their combination, respectively. The significant differences between the observed and expected mortality were defined through significance of the chi square values calculated through following equation

$$
\text { Chi square }\left(\chi^{2}\right)=\frac{\left(M_{\mathrm{AB}}-M_{\mathrm{e}}\right) \times 100 \times\left(M_{\mathrm{AB}}-M_{\mathrm{e}}\right)}{M_{\mathrm{e}}}
$$

Then $P$-values were looked up in chi square table for $\mathrm{df}=1$.

If the $M_{\mathrm{AB}}$ was significantly lower than $M_{\mathrm{e}}$ (when the calculated $\chi^{2}$ was lower than expected $\chi^{2}$ value observed from chi square table), it meant antagonism. If the $M_{\mathrm{AB}}$ was significantly higher than $M_{\mathrm{e}}$ (when the calculated $\chi^{2}$ was higher than expected $\chi^{2}$ value observed from chi square table), it meant synergism. Otherwise the mortality was additive (Xu et al., 2011).

\section{RESULTS}

\section{Influence of Matrine on Conidial Germination and Radial Growth of B. brongniartii}

Different concentrations of matrine had a non-significant effect on germination rate (\%) of $B$. brongniartii when compared with control. The highest rate of germination (97 $\pm 0.086 \%$ ) was observed for control whereas the lowest was observed for matrine concentration of $1.00 \mathrm{mg} / \mathrm{L}$ with mean value of $84 \pm 3.37 \%$ (Figure 1).

The average daily mycelial growth of $B$. brongniartii was not significantly affected by different matrine concentrations (except $1.0 \mathrm{mg} / \mathrm{ml})$ when compared with control $(F=45.72$; $\mathrm{df}=5.12 ; P=0.049)$. The highest average daily radial growth $(4.53 \pm 0.13 \mathrm{~mm} /$ day) was observed in the control whereas the lowest germination was observed for matrine concentration of $1.00 \mathrm{mg} / \mathrm{L}$ with a mean value of $4.13 \pm 0.08 \mathrm{~mm} /$ day (Figure 2).

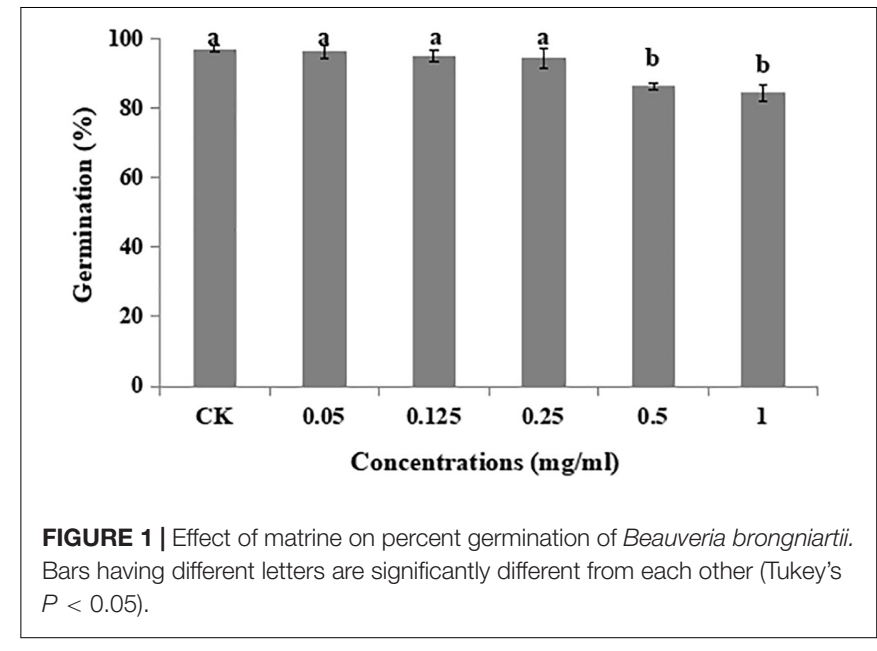

\section{Efficacy of B. brongniartii Against}

\section{S. litura}

Average cumulative mortality of 2 nd instar $S$. litura larvae in response to $B$. brongniartii differed significantly at different time intervals $\left(F_{2,28}=33.68, P<0.01\right)$. Average cumulative mortality of 2 nd instar $S$. litura larvae at different time intervals differed significantly among different concentrations of $B$. brongniartii $\left(F_{4,28}=68.95, P<0.01\right)$. The interaction effect between different time intervals and different $B$. brongniartii concentrations for mortality of 2 nd instar $S$. litura larvae was also significant statistically $\left(F_{8,28}=25.61, P<0.01\right)$. The highest mortality rates after 3, 5, and 7 days after fungal treatment were observed for conidial concentration of $1 \times 10^{9}$ conidia $/ \mathrm{mL}$; whereas lowest mortalities were observed for conidial concentration of $1 \times 10^{5}$ conidia/mL (Figure 3 ). Based on the above mortality data, the concentration-mortality response regression analysis for $B$. brongniartii was carried out to calculate the medial lethal concentration $\left(\mathrm{LC}_{50}\right)$. The $\mathrm{LC}_{50}$ value of $B$. brongniartii against $S$. litura was $1.4 \times 10^{8}$ conidia/mL after 7 days of fungal application.

\section{Efficacy of Matrine Against S. litura}

The main effect of different matrine concentrations on mean cumulative adjusted mortality for 2 nd larval instar of $S$. litura was significant $\left(F_{4,28}=48.80, P<0.01\right)$. The time duration after matrine application also showed a significant effect on mean cumulative adjusted mortality for 2nd larval instar of S. litura $\left(F_{2,28}=29.36, P<0.01\right)$. Similarly, there was a significant interaction effect on $S$. litura mortality involving matrine concentrations and time duration $\left(F_{8,28}=31.91\right.$, $P<0.01)$. The highest mortality rates after 3, 5, and 7 days post treatment were observed for concentration of $1.00 \mathrm{mg} / \mathrm{L}$ whereas, lowest mortalities were observed for conidial concentration of $0.05 \mathrm{mg} / \mathrm{L}$ (Figure 4). Based on the above mortality data, the concentration-mortality response regression analysis for matrine was carried out to calculate the medial lethal concentration $\left(\mathrm{LC}_{50}\right)$. The $\mathrm{LC}_{50}$ value of matrine against S. litura was $0.80 \mathrm{mg} / \mathrm{L}$. 

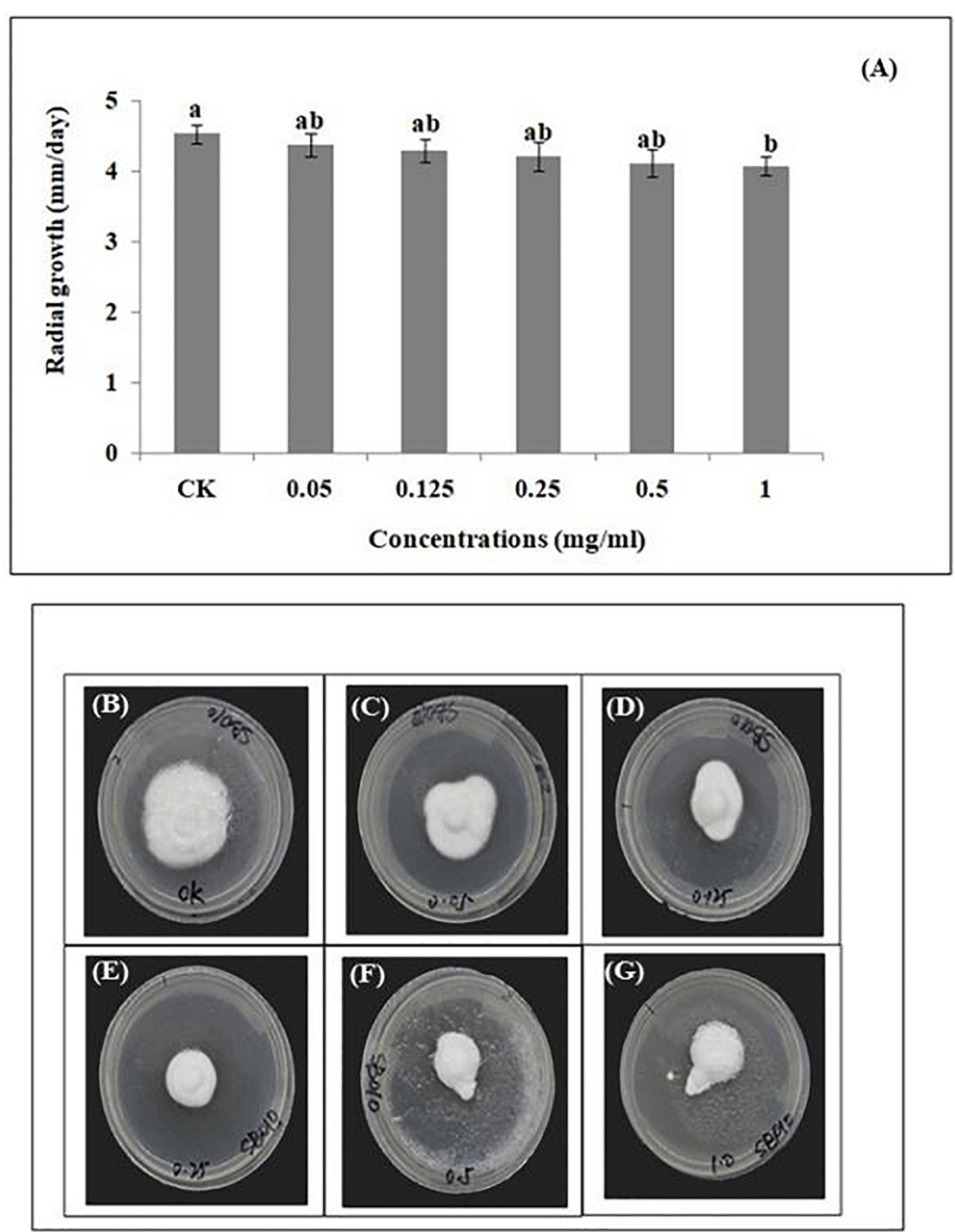

FIGURE 2 | Effect of matrine on radial growth of Beauveria brongniartii. (A) Radial growth (mm/day) in response to different matrine concentrations; (B-G) Growth of Beauveria brongniartii on different PDA plates having different matrine concentrations. Bars having different letters are significantly different from each other (Tukey's $P<0.05)$

\section{Efficacy of $B$. brongniartii and Matrine Alone or in Combination With Each Other Against S. litura Under Laboratory Conditions}

The different $B$. brongniartii and matrine joint treatment showed combinations significantly higher mortalities of 2nd instar S. litura larvae when compared with control as well as individual treatments of $B$. brongniartii or matrine $\left(F_{7,48}=39.91, P<0.01\right)$. The $S$. litura mortality in response to different $B$. brongniartii and matrine treatments (individual or joint treatments) under laboratory conditions differed significantly at different time intervals $\left(F_{2,48}=36.21, P<0.01\right)$ as did the interaction effect of different treatments and time intervals $\left(F_{14,48}=78.46, P<0.01\right)$. Moreover, joint treatments of $B$. brongniartii and matrine had a significant synergistic interaction at different time interval ( 3 , 5 , and 7 days) post treatment as the mortality values observed for combined treatments were significantly higher than expected mortality values (Table 2 ). The mortality symptoms of $S$. litura treated with $B$. brongniartii and matrine alone or in combination 

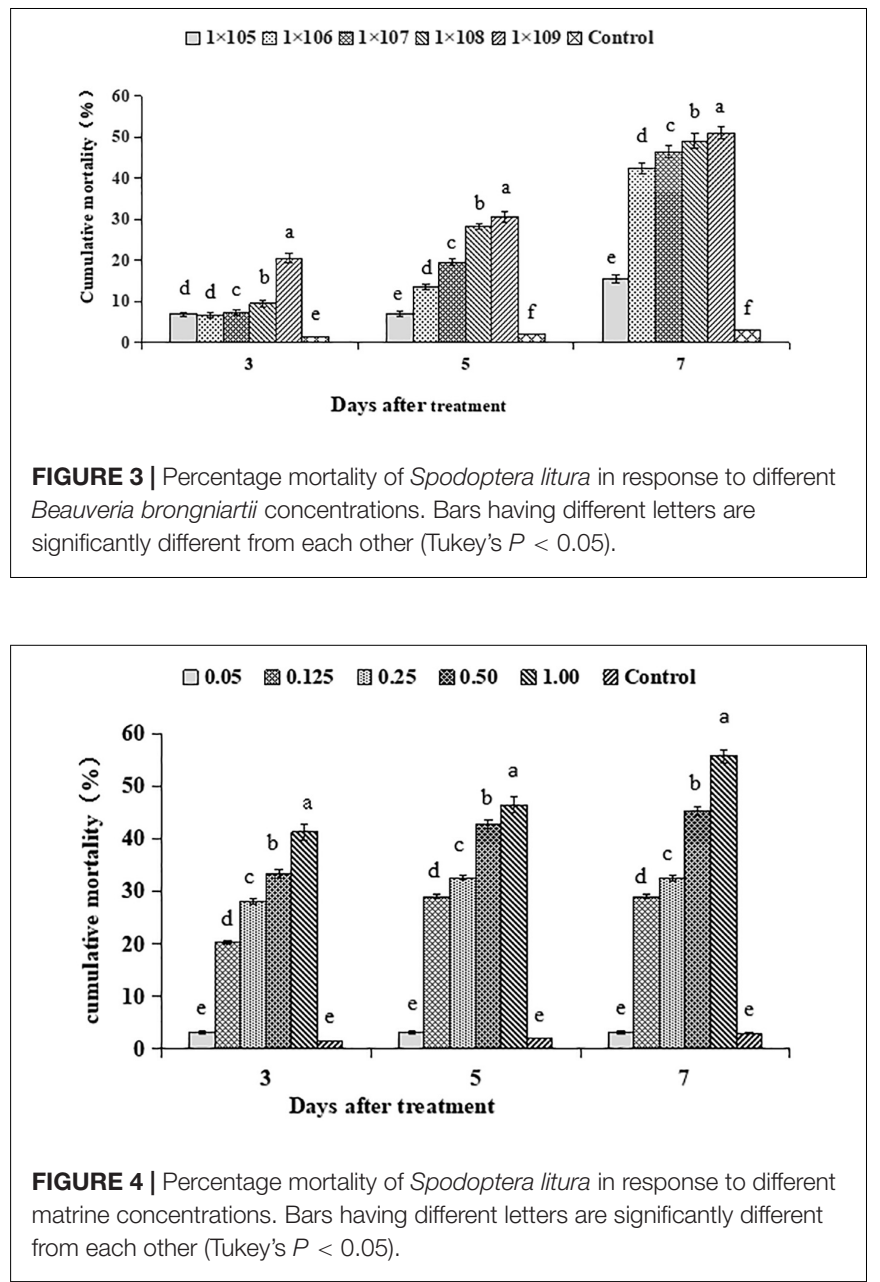

with each other are shown in Figure 5. The highest S. litura mortality (100\%) was observed for T8 after 7 days of treatment whereas lowest $S$. litura mortality $(9.43 \%)$ was observed for T3 after 3 days of fungal application. The rates of mortality observed for T6, T7, and T8 were statistically at par after 7 days of treatment (Table 2).

\section{Efficacy of B. brongniartii and Matrine Alone or in Combination With Each Other Against S. litura Under Semi-Field Conditions}

The S. litura mortality in response to different $B$. brongniartii and matrine treatments (individual or joint treatments) under semi-field conditions differed significantly at different time intervals $\left(F_{2,48}=51.77, P<0.01\right)$. The different $B$. brongniartii and matrine joint treatment showed combinations significantly higher mortalities of 2 nd instar $S$. litura larvae when compared with the control as well as individual treatments of $B$. brongniartii or matrine $\left(F_{7,48}=47.08, P<0.01\right)$. Similarly there was a significant interaction effect on $S$. litura mortality involving different treatment and time intervals $\left(F_{14,48}=42.57, P<0.01\right)$. Moreover, joint treatments of $B$. brongniartii and matrine showed a significant synergistic interaction at different time intervals (3, 5 , and 7 days) post treatment as the mortality values observed for combined treatments were significantly higher than expected mortality values (Table 2). The highest S. litura mortality (89.25\%) was observed for T8 after 7 days of treatment whereas lowest S. litura mortality (6.67\%) was observed for T3 after 3 days of fungal application. The rates of mortality observed for T7 and T8 were statistically at par after 7 days of treatment (Table 3 ).

\section{DISCUSSION}

Previous studies on $B$. brongniartii have only explained the pathogenic ability as well as lethal and sub lethal effects of this fungi against different insect pests (Fan et al., 2013; Goble et al., 2015; Mayerhofer et al., 2015; Soni et al., 2017). However, very few studies have elaborated the possible compatibility of B. brongniartii with natural chemicals (derived from plant or any other living organism) and other chemicals with novel mode of action (Sushil et al., 2018).This study reports the synergistic interaction of $B$. brongniartii with matrine (plant derived chemical) against $S$. litura under laboratory as well as semi field conditions.

Different concentrations of matrine were tested for their influence on the radial growth and conidial germination rates

TABLE 2 | Mean percent adjusted mortality of instar Spodoptera litura on mixtures of Beauveria brongniartii and matrine under laboratory conditions.

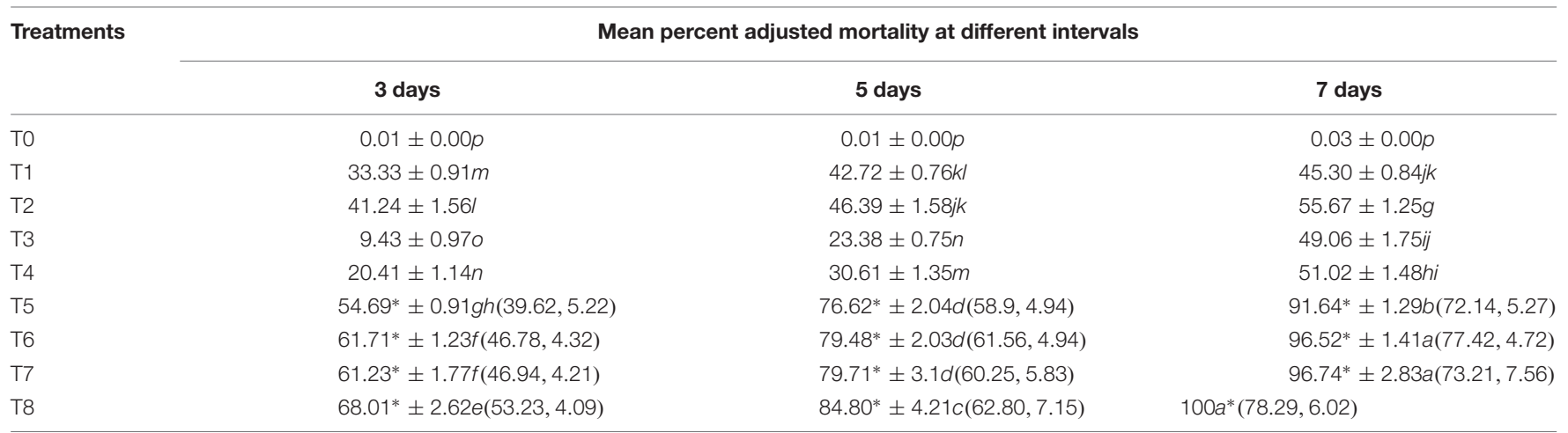

For treatment details see Table 1. Means ( $M \pm S E$ ) followed by different letters are significantly different (Tukey's $P<0.05)$. Data in brackets shows the expected mortality and the chi-square value, respectively. * represent the combined treatment having synergistic interaction through data analysis. 

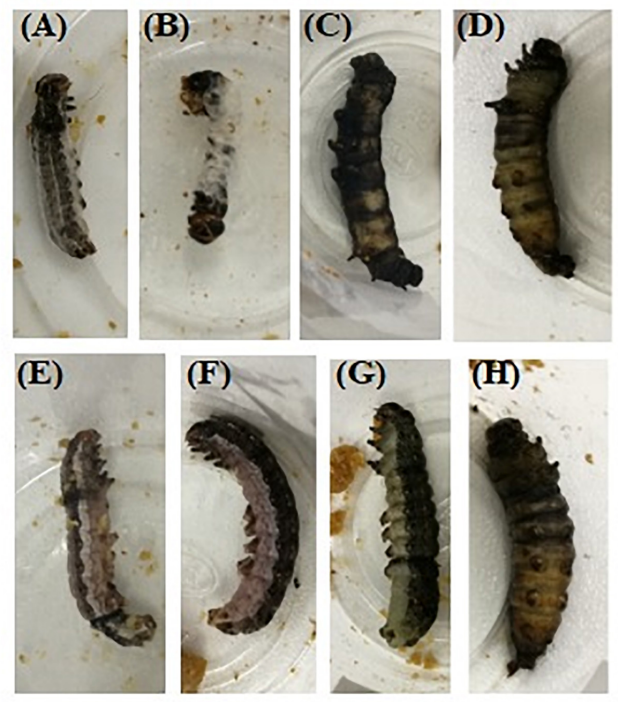

FIGURE 5 | Mortality symptoms of $S$. litura after 5 days of treatment with Beauveria brongniartii and matrine alone or in combination with each other (A) B. brongniartii $1 \times 10^{8}$ conidia/mL; (B) B. brongniartii $1 \times 10^{9}$ conidia $/ \mathrm{mL}$; (C) Matrine $0.5 \mathrm{mg} / \mathrm{mL}$; (D) Matrine $1.0 \mathrm{mg} / \mathrm{mL}$; (E) B. brongniartii $1 \times 10^{8}$ conidia $/ \mathrm{mL}+$ Matrine $0.5 \mathrm{mg} / \mathrm{mL}$ (F) B. brongniartii $1 \times 10^{8}$ conidia $/ \mathrm{mL}+$ Matrine $1.0 \mathrm{mg} / \mathrm{mL}$; (G) B. brongniartii $1 \times 10^{9}$ conidia $/ \mathrm{mL}+$ Matrine $0.5 \mathrm{mg} / \mathrm{mL}$, and (H) B. brongniartii $1 \times 10^{9}$ conidia $/ \mathrm{mL}+$ Matrine $1.0 \mathrm{mg} / \mathrm{mL}$.

of $B$. brongniartii. The results showed a low inhibition of radial growth and percent conidial germination. These results are similar to the findings of Xu et al. (2011) who observed similar effects of botanical extract 20-Hydroxyecdysone (derived from the plant, Ajuga nipponensis Makino) on growth and conidial germination of entomopathogens Isaria fumosorosea.

The main reason behind testing the efficacy of different conidial concentrations was to observe the pathogenic potential of $B$. brongniartii against 2 nd instar larvae of S. litura and to find out the optimum conidial concentration of $B$. brongniartii to be used in subsequent experiments. Our results showed that 2nd instar larvae of $S$. litura were susceptible to $B$. brongniartii having a median concentration value of $1.4 \times 10^{8}$ conidia/mL after 7 days of fungal application. These results are different from the findings of Liu et al. (2016) who observed LC $_{50}$ values of $7.28 \times 10^{7}$ and $3.85 \times 10^{7}$ conidia/ml against $X$. nigrum and A. ypsilon, respectively. Our findings are also different from Dhar et al. (2019) who observed $\mathrm{LC}_{50}$ value of $9.35 \times 10^{4}$ conidia/mL for B. bassiana isolate BbR2 against $S$. litura after 7 days of fungal application. Different matrine concentrations were tested for their toxicity against the population of $S$. litura reared at Key laboratory of biopesticides innovation and application of Guangdong Province, South China Agricultural University, Guangzhou, China under standard laboratory conditions. Based on the above mortality data, the medial lethal concentration $\left(\mathrm{LC}_{50}\right)$ of matrine against $S$. litura was $0.80 \mathrm{mg} / \mathrm{L}$ after 7 days of application. The $\mathrm{LC}_{50}$ of matrine against $S$. litura observed are slightly higher than the $\mathrm{LC}_{50}$ values of matrine against $S$. litura $(0.45 \mathrm{ml} / \mathrm{L})$ observed by Han et al. (2015). The variation in $\mathrm{LC}_{50}$ values may be explained by the changes in insect populations or difference in ecological niche of the tested insect populations. Our results are similar to the findings of Ali et al. (2017) who observed LC50 value of $0.83 \mathrm{mg} / \mathrm{L}$ against Bemisia tabaci Gennadius.

The interaction of entomopathogenic fungi with plant derived chemicals have been assessed through different mathematical models (Finney, 1971; Tabashnik, 1992).However, selection of earlier used models might not be feasible for this study as mortality of mixture comes from two sources (Xu et al., 2011) as B. brongniartii and matrine are known to target insect acetylcholine (Ach) receptors ultimately killing the insect through failure in acetylcholinesterase production (Liu et al., 2007; Xu et al., 2009). Joint application of B. brongniartii and matrine against $S$. litura caused a significant increase in mortality values under laboratory as well as field conditions, showing a strong synergistic interaction. The level of synergism shown by this study are consistent with Ali et al. (2017) who observed similar increase in mortalities of $B$. tabaci treated with different combinations of matrine and Lecanicillium muscarium. The level of synergism observed under semi-field conditions was slightly lower than the laboratory conditions which can be explained by the variations in different biotic and abiotic factors or behavior of the target pest under semi field conditions (Xu et al., 2011). Our

TABLE 3 | matrine under field conditions.

\begin{tabular}{lccc}
\hline Treatments & \multicolumn{3}{c}{ Mean percent adjusted mortality at different intervals } \\
\cline { 2 - 4 } & $\mathbf{3}$ days & $\mathbf{5}$ days & $\mathbf{7}$ days \\
\hline T0 & $0.10 \pm 0.00 p$ & $0.10 \pm 0.00 p$ & $0.0 .20 \pm 0.00 p$ \\
T1 & $27.04 \pm 0.87 m$ & $39.12 \pm 0.91 k$ & $44.23 \pm 1.02 j$ \\
T2 & $37.51 \pm 1.23 k$ & $43.57 \pm 1.39 j$ & $52.38 \pm 1.39 i$ \\
T3 & $6.67 \pm 0.940$ & $16.67 \pm 2.53 n$ & $30.00 \pm 2.30 / m$ \\
T4 & $16.67 \pm 1.63 n$ & $30.00 \pm 2.22 / m$ & $31.67 \pm 1.79 /$ \\
T5 & $50.00^{*} \pm 4.16 i(31.8,6.31)$ & $67.00^{*} \pm 5.2 f(49.25,5.39)$ & $79.52^{*} \pm 4.72 c(62.13,4.58)$ \\
T6 & $59.33^{*} \pm 5.88 h(41.66,7.20)$ & $71.00^{*} \pm 4.05 e(53.08,5.04)$ & $87.67^{*} \pm 4.79 a(66.61,6.24)$ \\
T7 & $62.3^{*} \pm 3.74 \operatorname{gh}(39.16,6.59)$ & $75.19^{*} \pm 0.52 d(57.37,5.41)$ & $83.51^{*} \pm 4.70 b(62.99,6.35)$ \\
T8 & $65.30 \pm 3.17 f(47.91,6.08)$ & $77.05 \pm 5.83 c d(60.59,4.44)$ & $89.25^{*} \pm 4.95 a(67.37,6.94)$
\end{tabular}

For treatment details see Table 1. Means $(M \pm S E)$ followed by different letters are significantly different (Tukey's $P<0.05)$. Data in brackets shows the expected mortality and the chi-square value, respectively. * represent the combined treatment having synergistic interaction through data analysis. 
results are also similar to the studies of Han et al. (2015). Their results demonstrated significantly higher S. exigua mortality for the mixtures of botanicals (matrine or neem) with Bacillus thuringiensis when compared with control and only botanicals (matrine or neem) treatments.

\section{CONCLUSION}

Our findings reports promising results for combined application of $B$. brongniartii and matrine in controlled as well as field conditions. These results will provide baseline information for the development as well as utilization of botanical + microbial insecticide based formulations in S. litura management programs. However, further studies are required for the detailed elaboration of sublethal effects of the matrine and $B$. brongniartii on growth and development of $S$. litura as well as the physiological processes involved in the said synergistic effect.

\section{DATA AVAILABILITY}

The raw data supporting the conclusions of this manuscript will be made available by the authors, without undue reservation, to any qualified researcher.

\section{REFERENCES}

Abbott, W. S. (1925). A new method for computing the effectiveness of an insecticide. J. Econ. Entomol. 18, 265-267. doi: 10.1093/jee/18.2.265a

Ahmad, M., and Mehmood, R. (2015). Monitoring of resistance to new chemistry insecticides in Spodoptera litura (Lepidoptera, Noctuidae) in Pakistan. J. Econ. Entomol. 108, 1279-1288. doi: 10.1093/jee/tov085

Ali, S., Huang, Z., and Ren, S. X. (2009). Media composition influences on growth, enzyme activity, and virulence of the entomopathogen hyphomycete Isaria fumosoroseus. Entomol. Exp. Appl. 131, 30-38. doi: 10.1111/j.1570-7458.2009. 00833.x

Ali, S., Zhang, C., Wang, Z. Q., Wang, X. M., Wu, J. H., Cuthbertson, A. G. S., et al. (2017). Toxicological and biochemical basis of synergism between the entomopathogenic fungus Lecanicillium muscarium and the insecticide matrine against Bemisia tabaci(Gennadius). Sci. Rep. 7:46558. doi: 10.1038/srep46558

Borja, M. R., Franco, A. W. G., Leyva, E. R., Ortega, C. S., and Panduro, A. P. (2018). Interaction of Beauveria bassiana and Metarhizium anisopliae with chlorpyrifos ethyl and spinosid in Spodoptera frugiperda larvae. Pest Manag. Sci. 74, 2047-2052. doi: 10.1002/ps.4884

Chao, F., Wang, D. E., Liu, R., Tu, Q., Liu, J. J., and Wang, J. Y. (2013). Synthesis, characterization and activity evaluation of matrinic acid derivatives as potential anti-proliferative agents. Molecules 18, 5420-5433. doi: 10.3390/ molecules 18055420

Chaudhari, C. S., Chandele, A. G., Pokharkar, D. S., Dethe, M. D., and Firake, D. M. (2016). Pathogenicity of different isolates of entomopathogenic fungus, Nomuraea rileyi (Farlow) samson against tobacco caterpillar, Spodoptera litura (Fabricius). Proc. Natl. Acad. Sci. India Sect. B Biol. Sci. 86, 1001-1007. doi: 10.1007/s40011-015-0537-6

Cheng, X., Ye, J., He, H., Liu, Z., Xu, C., Wu, B., et al. (2018). Synthesis, characterization and in vitro biological evaluation of two matrine derivatives. Sci. Rep. 8:15686. doi: 10.1038/s41598-018-33908-8

David, W., Ellaby, S., and Taylor, G. (1975). Rearing Spodoptera exempta on semi synthetic diets and on growing maize. Entomol. Exp. Appl. 19, 226-236.

Dhar, S., Jindal, V., Jaryal, M., and Gupta, V. K. (2019). Molecular characterization of new isolates of the entomopathogenic fungus Beauveria bassiana and their efficacy against the tobacco caterpillar, Spodoptera litura (Fabricius) (Lepidoptera: Noctuidae). Egypt. J. Biol. Pest Control. 29:8.

\section{AUTHOR CONTRIBUTIONS}

JW and SA conceived and designed the research. XY and XW conducted the experiments. LT and SA analyzed the data. SA wrote the manuscript. All authors read and approved the manuscript.

\section{FUNDING}

This research was supported by grants from the Innovation and Development Project of Hunan Yongzhou Tobacco Co. Ltd., the National Natural Science Foundation (31750110475), Science and Technology Program of Guangzhou, China (201807010019 and 201804020070), and Gaungdong Province Science and Technology Innovation Strategy Special Fund (2018B020206001).

\section{ACKNOWLEDGMENTS}

The authors want to thank Dr. Andrew G. S. Cuthbertson for editing the language of the manuscript.

Fan, J. H., Xie, Y. P., Xue, J. L., Zhang, Y. L., and Liu, R. (2013). The effect of Beauveria brongniartii and its secondary metabolites on the detoxifaction enzymes of the pine caterpillar Dendrolimus tabulaeformis. J. Insect Sci. 13, 1-13. doi: 10.1673/031.013.4401

Finney, D. J. (1971). Probit Analysis. Cambridge: Cambridge University Press.

Goble, T. A., Conlong, D. E., and Hill, M. P. (2015). Virulence of Beauveria brongniartii and B. bassiana against Schizonycha affinis white grubs and adults (Coleoptera: Scarabaeidae). J. Appl. Entomol. 139, 134-145. doi: 10.1111/jen. 12182

Gupta, R. B. L. (2002). "Fungal pathogens in the management of white grubs and other soil dwelling pests," in Indian Phytophagous Scarabs and their Management: Present Status and Future Strategy, eds G. Sharma, and Y. S. Mathur, (Jodhpur: Agrobios India), 17-39.

Han, H. H., Yoon, J., Son, S., Kim, J., and Lee, S. Y. (2015). Combination effects of organic materials and Bacillus thuringiensis on Spodoptera exigua. Korean J. Pestic. Sci. 4, 411-417. doi: 10.7585/kjps.2015.19. 4.411

Hu, H., Wang, S., Zhang, C., Wang, L., Ding, L., Zhang, J., et al. (2010). Synthesis and in vitro inhibitory activity of matrine derivatives towards pro-inflammatory cytokines. Bioorg. Med. Chem. Lett. 24, 7537-7539. doi: 10.1016/j.bmcl.2010. 09.075

Huang, L. P. (2019). Identification of 29 Beauveria isolates and their Virulence Against Bemisia tabaci. M.Sc thesis, South China Agricultural University, Guangzhou.

Hwang, I. C., Kim, J., Kim, H. M., Kim, D. I., Kim, S. G., Kim, S. S., et al. (2009). Evaluation of toxicity of plant extract made by neem and matrine against main pests and natural enemies. Kor. J. Appl. Entomol. 48, 87-94. doi: 10.5656/ksae. 2009.48.1.087

Ishtiaq, M., Saleem, M. A., and Razaq, M. (2012). Monitoring of resistance in Spodoptera exigua (Lepidoptera: Noctuidae) from four districts of the Southern Punjab, Pakistan to four conventional and six new chemistry insecticides. Crop. Prot. 33, 13-20. doi: 10.1016/j.cropro.2011. 11.014

Kaur, M., Chadha, P., Kaur, S., Kaur, A., Kaur, R., Yadav, A. K., et al. (2019). Evaluation of genotoxic and cytotoxic effects of ethyl acetate extract of Aspergillus flavus on Spodoptera litura. J. Appl. Microbiol. 126, 881-893. doi: 10.1111/jam.14105 
Leathers, T. D., Gupta, S. C., and Alexander, N. J. (1993). Mycopesticides: status, challenges and potential. J. Ind. Microbiol. 12, 69-75. doi: 10.1007/bf0156 9904

Li, S. G., Hau, R. M., Lin, H. F., Cao, H. Q., Hu, J., and Hu, P. (2010). Control effects of four biological pesticides and two chemical pesticides and their mixtures against mixed population of Nilaparvata lugens and Sogatella furcifera. Chin. Bull. Entomol. 47, 768-772.

Liu, C. H., Wang, Y. W., Yu, H. C., Sun, Y. F., Hou, Y. M., Zhao, K. J., et al. (2016). Toxicity of Beauveria brongniartii to two cutworm species. Chin. J. Appl. Entomol. 53, 739-744.

Liu, Z. L., Goh, S. H., and Ho, S. H. (2007). Screening of Chinese medicinal herbs for bioactivity against Sitophilus zeamais Motschulsky and Tribolium castaneum (Herbst). J. Stored Prod. Res. 43, 290-296. doi: 10.1016/j.jspr.2006.06.010

Mao, L. X., and Henderson, G. (2007). Antifeedant activity and acute and residual toxicity of alkaloids from Sophora flavescens (Leguminosae) against Formosan subterranean Termites (Isoptera: Rhinotermitidae). J. Econ. Entomol. 100, 866870. doi: 10.1603/0022-0493(2007)100\%5B866:aaaaar\%5D2.0.co;2

Mayerhofer, J., Enkerli, J., Zelger, R., and Strasser, H. (2015). Biological control of the European cockchafer: persistence of Beauveria brongniartii after long term application in the Euroregion Tyrol. Biocontrol 60, 617-629. doi: 10.1007/ s10526-015-9671-6

Nakajyo, S., Shimizu, K., Kometani, A., Suzuki, A., Ozaki, H., and Urakawa, N. (1983). On the inhibitory mechanism of bassianolide, a cyclodepsipeptide, in acetylcholine-induced contraction in guinea pig taenia coli. Jpn. J. Pharmacol. 33, 573-582. doi: 10.1254/jjp.33.573

Namasivayam, S. K. R., Bharani, R. S. A., and Karunamoorthy, K. (2018). Insecticidal fungal metabolites fabricated chitosan nanocomposite (IM-CNC) preparation for the enhanced larvicidal activity - An effective strategy for green pesticide against economic important insect pests. Int. J. Biol. Macromol. 120, 921-944. doi: 10.1016/j.ijbiomac.2018.08.130

Nguyen, H. C., Tran, T. V., Ngyuen, Q. L., Nguyen, N. N., Nguyen, M. K., Nguyen, N. T. T., et al. (2017). Newly Isolated Paecilomyces lilacinus and paecilomyces javanicus as novel biocontrol agents for plutella xylostella and Spodoptera litura. Notu. Bot. Hort. Agrobot. Clujnapoca. 45, 280-286. doi: $10.15835 /$ nbha45110726

Ou, D. (2019). Toxicity Evaluation of Entomopathogenic Fungi Against Asian Citrus Psyllid. M.Sc thesis, South China Agricultural University, Guangzhou.

Qing, H. G., Wang, D. D., Ding, J., Huang, R. H., and Ye, Z. X. (2006). Host plants of Spodoptera litura. Acta Agr. Jiangxi 18, 51-59.

Revathi, K., Chandrasekaran, R., Thanigaivel, A., Kirubakaran, S. A., and Nathan, S. S. (2014). Biocontrol efficacy of protoplast fusants between Bacillus thuringiensis and Bacillus subtilis against Spodoptera litura Fabr. Arch. Phytopathol. Plant Prot. 47, 1365-1375.

Sahayaraj, K., Subash, N., Allingham, R. W., Kumar, V., Avery, P. B., Mehra, L. K., et al. (2018). Lethal and sublethal effects of three microbial biocontrol agents on Spodoptera litura and its natural predator Rhynocoris kumarii. Insects 9:101. doi: 10.3390/insects9030101

SAS Institute, (2000). "SAS User's Guide”in: Statistics. Cary, NC: SAS Institute.

Soni, S., Mehta, P. K., and Chandel, R. S. (2017). Suceptibility of white grub, Brahmina coriacea (Hope) infesting potato to local strains of Beauveria brongniartii (Saccardo) in Himachal Prades. J. Biol. Control 32, 41-47.

Sun, D. Q., Wang, J., Yang, N. D., and Ma, H. X. (2016). Matrine suppresses airway inflammation by down regulating SOCS3 expression via inhibition of NF- $\kappa$ B signaling in airway epithelial cells and asthmatic mice. Biochem. Biophys. Res. Commun. 477, 83-90. doi: 10.1016/j.bbrc.2016.06.024

Sushil, S. N., Josh, D., Tripathi, G. M., Singh, M. R., Baitha, A., Rajak, D. C., et al. (2018). Exploring efficacious microbial bio-agents and insecticides against white grubs in sugarcane in indo-gangetic plains. Sugar Tech. 20, 552-557. doi: 10.1007/s12355-017-0556-0

Tabashnik, B. E. (1992). Evaluation of synergism among Bacillus thuringiensis toxins. Appl. Environ. Microb. 58, 3343-3346.
Thomas, M. B., and Read, A. F. (2007). Can fungal biopesticides control malaria? Nat. Rev. Microbiol. 5, 377-383. doi: 10.1038/nrmicrol638

Vidal, C., Osborne, L. S., Lacey, L. A., and Fargues, J. (1998). Effect of host plant on the potential of Paecilomyces fumosoroseus (Deuteromycotina: Hyphomycetes) for controlling the silver leaf whitefly, Bemisia argentifolii (Homoptera: Aleyrodidae) in greenhouses. Biol. Control 12, 191-199. doi: 10.1006/bcon. 1998.0625

Wada, S., Mikuni, T., Tamura, H., Yukuhiro, F., Murakami, R., Mitsuhashi, W., et al. (2010). Differences in the susceptibility among silkworm, Bombyx mori (Lepidoptera: Bombycidae), strains to the entomopathogenic fungus, Beauveria brongniartii and the mode of the inheritance of the susceptibility. J. Insect Biotecnol. Sericol. 79, 103-110.

Wada, S., Mitsuhashi, W., Miyamoto, K., and Kunimi, Y. (2016). Immune response in the hemocyte after phagocytosis influences the infection with Beauveria brongniartii to the silkworm, Bombyx mori. J. Insect Biotecnol. Sericol. 85, 55-65.

Wang, J. J., Cheng, W. X., Ding, W., and Zhao, Z. M. (2004). The effect of the insecticide dichlorvos on esterase activity extracted from the psocids, Liposcelis bostrychophila and L. entomophila. J. Insect Sci. 4:23.

$\mathrm{Xu}$, D., Ali, S., and Huang, Z. (2011). Insecticidal activity influence of 20-Hydroxyecdysone on the pathogenicity of Isaria fumosorosea against Plutella xylostella. Biol. Control 56, 239-244. doi: 10.1016/j.biocontrol.2010. 11.011

Xu, Y. Q., Orozco, R., Wijerante, E. M. K., Espinosa-Artiles, P., Lesile Gunatilaka, A. A., Stock, S. P., et al. (2009). Biosynthesis of the cyclooligomer depsipeptide bassianolide, an insecticidal virulence factor of Beauveria bassiana. Fungal Gen. Biol. 46, 353-364. doi: 10.1016/j.fgb.2009.03.001

Yang, H., Qin, C. S., Chen, Y. M., Zhang, G. Y., Dong, L. H., and Wan, S. Q. (2019). Persistence of metarhizium (Hypocreales: Clavicipitaceae) and Beauveria bassiana (Hypocreales: Clavicipitaceae) in tobacco soils and potential as biocontrol agents of Spodoptera litura (Lepidoptera: Noctuidae). Environ. Entomol. 48, 147-155. doi: 10.1093/ee/nvy161

Yang, X., and Zhao, B. (2006). Antifungal activities of matrine and oxymatrine and their synergetic effects with chlorthalonil. J. For. Res. 17, 323-325. doi: 10.1007/s11676-006-0074-5

Zanardi, O. Z., Ribeiro, L. D. P., Ansante, T. F., Santos, M. S., Bordini, G. P., Yamamotoa, P. T., et al. (2015). Bioactivity of a matrine-based biopesticide against four pest species of agricultural importance. Crop Prot. 67, 160-167. doi: 10.1016/j.cropro.2014.10.010

Zhang, P., Gao, M., Mu, W., Zhou, C., and Li, X. H. (2014). Resistant levels of Spodoptera exigua to eight various insecticides in Shandong, China. J. Pesticid. Sci. 39, 7-13. doi: 10.1584/jpestics.d13-053

Zhang, S. H., Zhang, Y., Zhuang, Y., and Han, Y. X. (2012). Matrine induces apoptosis in human acute myeloid leukemia cells via the mitochondrial pathway and akt inactivation. PLoS One 7:e46853. doi: 10.1371/journal.pone.00 46853

Zhang, Y., Zhang, H., Yu, P. F., Liu, Q., Liu, K., Duan, H. Y., et al. (2009). Effects of matrine against the growth of human lung cancer and hepatoma cells as well as lung cancer cell migration. Cytotechnology 59, 191-200. doi: 10.1007/s10616009-9211-2

Conflict of Interest Statement: The authors declare that the research was conducted in the absence of any commercial or financial relationships that could be construed as a potential conflict of interest.

Copyright (c) $2019 \mathrm{Wu}, \mathrm{Yu}$, Wang, Tang and Ali. This is an open-access article distributed under the terms of the Creative Commons Attribution License (CC BY). The use, distribution or reproduction in other forums is permitted, provided the original author(s) and the copyright owner(s) are credited and that the original publication in this journal is cited, in accordance with accepted academic practice. No use, distribution or reproduction is permitted which does not comply with these terms. 